\title{
EXPERIMENTAL INVESTIGATION OF THE SHEAR RESISTANCE OF CONCRETE HINGES UNDER A BIAXIAL LOAD
}

Peter Havlíček1* , Július Šoltész' ${ }^{1}$ Jakub Gašpárek

\begin{abstract}
Concrete hinges can withstand extremely high loads and rotations, while requiring only minimal maintenance. Their use is widespread, mainly in bridge construction, but they also find applications in the prefabrication of tunnel segments. With the right design and implementation, they can meet the highest requirements for the durability and resistance of a structure. However, the existing models and design procedures are relatively outdated. The models are based solely on empirical assumptions, whereas the shear resistance of the joint itself plays only a marginal role. The following paper aims to compare existing design models against experimental results in order to find the most suitable design approach that reliably captures the performance of a hinge under a shear load. An experimental program was developed in which 9 samples of concrete hinges were tested for different levels of axial loads and degrees of reinforcement. The results of the experiments were then compared with the selected design models, and a numerical nonlinear analysis was conducted.
\end{abstract}

Address

1 Dept. of Concrete Structures and Bridges, Faculty of Civil Engineering, Slovak University of Technology in Bratislava, Slovakia

* Corresponding author: peter.havlicek@stuba.sk

\section{Key words}

- Concrete hinges,

- Shear resistance,

- Biaxial load.

\section{INTRODUCTION}

The shear resistance of concrete structures is a heavily debated issue, especially for common structures, such as slabs or beams. Correspondingly, a vast number of experimental programs and regulations for the design of these structures exist. Shear failure is one of the most dangerous types of failures due to its brittle nature and the possible progressive collapse of a whole structure, particularly when the failure occurs prior to the yielding of the main reinforcement. In bridges, concrete hinges are often treated as a secondary structure, so that sufficient attention is not dedicated to their design. One of the reasons for overlooking their design is the fact that during a standard working load of a bridge, the shear force applied to a hinge is several times lower than the axial and bending inner forces, although this may not apply to extraordinary design cases, such as a seismicity design.

The main problem is that all the existing design models are mainly based on empirical parameters and lack a clear physical substance. The main emphasis is placed on determining the limit rotation and the bending resistance. The shear resistance, however, is calculated only as a fraction of the limits of the axial resistance.

The existing design approaches can be divided into four categories based on their foundational design model. The first substantial category comprises regulations based on the Leonhardt model (Marx and Schacht, 2010), which includes a German model, the Dutch NEN 6723 regulation (NEN: NEN 6723, 1995); and the Swedish BVVVTK Bro 08 regulation (BVVVTK Bro 08 VV, 2008). The British CS 468 regulation (formerly BE 5/75) slightly differs from the German model and represents a more conservative design approach (CS 468, 2020). The last two categories consist of the M. Herzog model (Herzog, 2005) and the French Règles BAEL 91 model (Règles BAEL 91, 1999). None of the models listed above derive their shear resistance from their structural or material strength, but base their definition on the maximum allowable shear stress. This value depends only on the axial force at the hinge throat regardless of the geometry, reinforcement or material properties. An overview of the design formulas according to the individual models is given in the following table: 
Tab. 1 Shear resistance according to the existing design models

\begin{tabular}{|l|l|l|l|}
\hline Model type & Label & Reinforcement & Shear resistance \\
\hline $\begin{array}{l}\text { German model - F. Leonhard } \\
\begin{array}{l}\text { Dutch model - NEN 6723 } \\
\text { Swedish model -BVVVTK Bro '08 }\end{array}\end{array}$ & $\mathrm{V}_{\mathrm{R}, \mathrm{N}}$ & If: $\mathrm{V} \geq 0.125 \mathrm{~N}$ & $\mathrm{~V}_{\mathrm{R}}=0.25 \mathrm{~N}$ \\
\hline British model - BE 5/75 & $\mathrm{V}_{\mathrm{R} . \mathrm{B}}$ & $-\mathrm{V}_{\mathrm{R} . \mathrm{B}}$ & $\mathrm{V}_{\mathrm{R}}=1 / 3 \mathrm{~N}$ \\
\hline French model - BAEL 91 modifiées 99 & $\mathrm{V}_{\mathrm{R} . \mathrm{F}}$ & - & $\mathrm{V}_{\mathrm{R}}=0.25 \mathrm{~N}$ \\
\hline M. Herzog model & $\mathrm{V}_{\text {R.H }}$ & - & $\mathrm{V}_{\mathrm{R}}=\left(\frac{3}{4}-\mathrm{a}\right) \mathrm{N}+\frac{\mathrm{f}_{\mathrm{yk}} \mathrm{A}_{\mathrm{s}}}{\sqrt{3}}$ \\
\hline
\end{tabular}

where: $a$ is the length of the hinge throat

$\mathrm{N}$ - normal axial force at the hinge throat

$\mathrm{f}_{\mathrm{yk}}$ - yield strength of the reinforcement

$\mathrm{A}_{\mathrm{s}}$ - area of reinforcement at the hinge throat

According to the overview in Table 1, only the M. Herzog model takes into consideration the geometry and reinforcement of the hinge throat to some extent. The calculation of the resistance according to these models does not correspond with today's European standards or the current state of knowledge in the field of the shear resistance of concrete structures.

Based on the current state of the knowledge and with regard to the nature of the redistribution of the stress and failure mode during the shear loading of a concrete hinge, it is possible to use a theory hereinafter referred to as the "extended shear friction theory" (ESF) (Fib. Special Activity Group 5, 2011). This theory takes into account all the relevant mechanisms involved in the transfer of the shear forces in a shear crack. These include the adhesive bonds, aggregate interlocking, friction, and dowel effect of the reinforcement. The contribution of these mechanisms to the overall resistance is a function of the shear slip in the crack, degree of reinforcement, and surface roughness. Depending on these parameters, at least two main scenarios can be distinguished for a design.

- Scenario 1: Brittle behaviour ("rigid" bond-slip)

$$
\tau_{R u}(w \leq 0.05 \mathrm{~mm})=\tau_{R, \text { adhesion }}+\tau_{R, \text { friction }}
$$

This type of failure usually occurs at unreinforced or poorly reinforced interfaces, where the degree of reinforcement ranges from $0 \leq(\leq 0.05 \%$. At small values of a shear slip, the contribution of the adhesive bonds and friction dominate, while the contribution of the reinforcement and friction is almost negligible. With an increasing deformation, the effect of the adhesion rapidly decreases. The limit value of the slip in this case is $0.05-0.1 \mathrm{~mm}$. After exceeding this limit, the aggregate and cement matrix in the crack is mostly lost. In the case of unreinforced interfaces, the failure occurs around these slip value limits. The resulting collapse is sudden and brittle. The Coulomb shear friction hypothesis can be used as an appropriate failure criterion to describe the resistance resulting from the friction and adhesive bond, the latter of which is reasonably related to the tensile strength of the concrete in design Eq. (1) (Randl, 2013).

$$
T_{R d}=c_{a} \cdot f_{c t d}+\mu \delta_{n} \leq 0.5 \cdot v \cdot f_{c d}
$$

Where:

$c_{a} \quad$ is the coefficient of the adhesive bond

$f_{c t d}^{a}$ design tensile strength of the concrete, $f_{c d}=f_{c k} / \gamma \mathrm{c}$

$v$ reduction factor for the strength of a diagonal concrete strut,

$v \quad=0.55 .\left(30 / \mathrm{f}_{\mathrm{ck}}\right)^{1 / 3} \mathrm{v}(\mathrm{MPa})$

$\mu \quad$ - friction coefficient of shear interface

$\delta_{n} \quad-$ compressive stress due to external normal force (minimum guaranteed value)
The values of the adhesive bond coefficient vary between $0.025-0.5$, depending on the roughness of the shear interface. For reinforced interfaces, if the adhesive bond breaks down due to high shear loading, Scenario 1 is no longer applicable, and the design approach according to Scenario 2 therefore must be used. The adhesion and interlocking effect are replaced by three components, namely, the friction, the aggregate interlocking, and the bending resistance of the reinforcement at the interface (Randl, 2013).

- Scenario 2: Ductile behaviour ("non-rigid" bond-slip)

$$
\tau_{R u}(w)=\tau_{R, \text { interlocking }}+\tau_{R, \text { friction }}+\tau_{R, \text { reinforcement }}
$$

In this scenario a ductile failure can be observed, and a "non-rigid" bond slip occurs. In this case the shear resistance consists of several components. The contribution of the reinforcement or connectors in the interface slowly activates with the increasing deformation. With large slips, the resistance even increases due to the "kinking effect" of the reinforcement. The failure of the reinforced interface has a more ductile character with the slip value ranging between $0.5-1.5 \mathrm{~mm}$. The exact contribution of the individual mechanisms mainly depends on the quality of the concrete, the roughness of the interface, and the amount and type of the reinforcement. With high values of surface roughness, the component of the friction and aggregate interlock dominates, while conversely, at smooth interfaces, the contribution of the reinforcement predominates. In the case of concrete hinges, the conditions for the transmission of frictional forces will generally be very good, and the very rough interface could be considered, although the interface parameters depend to a large extent on the construction method and the concreting process applied for the hinge. The upper value of the shear resistance is limited by the resistance of the diagonal concrete strut in both scenarios. The Design equation for the diagonal compressive concrete strut used in Eq. (1) is applicable only for the truss structures such as slabs or girders therefore an applicability of this equation for the concrete hinges needs to be investigated further. The experimental investigation of the compressive concrete strut and assessment of existing design models can be found in (Halvoník, 2018). The design formula for the transferable shear stress in the shear crack at the hinge throat according to Scenario 2 is as follows (Randl, 2013):

$$
\begin{gathered}
\tau_{R u}=c_{r} \cdot f_{c k}^{1 / 3}+\mu \cdot \sigma_{n}+\kappa_{1} \cdot \rho \cdot f_{y d} \cdot(\mu \cdot \sin \alpha+\cos \alpha)+ \\
+\kappa_{2} \cdot \rho \cdot \sqrt{f_{c d} \cdot f_{y d}} \leq \beta_{c} \cdot v \cdot f_{c d}
\end{gathered}
$$

Where:

$c_{r}-$ coefficient of aggregate interlocking 
$\kappa_{1}-$ coefficient of efficiency for tensile force that can be activated in the reinf. $\kappa_{1}=\delta_{s} / f y \leq 1$.

$\kappa_{2}-$ coefficient for flexural resistance of the reinforcement (dowel action)

$\alpha$ - angle of reinforcement

$\rho$ - degree of joint reinforcement $\left(\rho=A_{s} / A_{c} ; A_{s}=\right.$ steel cross-section, $\mathrm{A}_{\mathrm{c}}=$ shear plane)

$f_{y d}$ - design yield strength of the reinforcement, $f_{y d}=f_{y k} / \gamma s$

$f_{c d}$ - design compression strength of the concrete, $f_{c d}=f_{c k} / \gamma c$

$\sigma_{n}$-compressive stress due to external normal force (minimum guaranteed value)

$v$ - reduction factor for strength of the diagonal concrete strut: $v=0.55 \cdot\left(30 / f_{c k}\right) 1 / 3 \leq 0.55$

$\beta_{\mathrm{c}}$ - coefficient allowing for the angle of the diagonal concrete

\section{DESCRIPTION OF THE EXPERIMENTAL PROGRAM}

The scope of the experimental program we conducted was to verify the applicability of the selected design models for calculating the shear resistance of the hinges and to verify their safety and reliability for designs. In the experimental program, nine concrete hinge test specimens subjected to normal and shear forces were tested. The test specimens were concrete prisms, which were $620 \mathrm{~mm}$ high with a bottom cross section of $400 \times 250 \mathrm{~mm}$. At the midpoint of the prism's height, the cross-section was symmetrically reduced to a rectangle with dimensions of $225 \times 75 \mathrm{~mm}$, thus creating a hinge throat. The height of the throat was $2 \mathrm{~cm}$. Three types of specimens were used in the experiment. Each type differed in the degree of reinforcement and the position of the rebars in the neck. The Type-1 sample was non-reinforced. The Type- 2 sample was unreinforced with $3 \phi 8$ bars in the centre, and the Type- 3 sample had $6 \phi 8$ bars placed in two rows. An overview of the test specimen types is in Table 2. Both sides of the hinge were strengthened by an additional reinforcement in order to avoid a transverse tension failure of the hinge, see Fig. 1a-1g.

\subsection{Setup of the Test}

The setup of the test consisted of a pair of steel supports where the specimens were placed. The loading was carried out using a pair of hydraulic presses. A vertical press was placed directly on the floor in the gap between the steel supports. On the other hand, a horizontal press was placed on one of the steel supports between a pair of horizontal beams that were interconnected with a pair of prestressing rods. To prevent the beams from being lifted during the loading, a set of cross beams was used to anchor them to the floor. Additional secondary support components, such as friction bearing or centering pads, were added after the specimen and the main steel frame were already set up, see Figs.2 and 3. A force cell with a capacity of 2000 $\mathrm{kN}$ was used for the vertical press and one with a capacity of $500 \mathrm{kN}$ for the horizontal press. Any displacements that occurred were measured with digital displacement gauges placed on the side of the test specimen. The loading was carried out in steps. First, the full axial force was applied. Then the shear force was applied in increments of $10 \mathrm{kN} / \mathrm{step}$ until failure. The values were recorded after each loading step and after the stabilization of the deformations. Each type of specimen was tested at three levels of axial force and the value of the normal stress in the joint neck $(50 \mathrm{kN}, 300 \mathrm{kN}$ and $450 \mathrm{kN})$, respectively. Higher values of the normal stress in the neck could not be achieved due to the limitations of the assembly and the measuring instruments used. The specimens were loaded only with centric pressure to eliminate any bending stress on the joint neck.

Tab. 2 Parameters of the test specimens

\begin{tabular}{|c|c|c|c|c|c|c|}
\hline Specimen type & Number (pc) & $f_{c}(\mathrm{MPa})$ & reinforcement & Degree of reinf. $\rho(\%)$ & $\mathrm{d}_{\max }(\mathrm{mm})$ & Position of reinf \\
\hline TYP-0 & 3 & \multirow{3}{*}{33.46} & $0 \phi 8$ & 0.0 & 16 & \\
\hline TYP-3 & 3 & & $3 \phi 8$ & 0.89 & 16 & $\bullet$ \\
\hline TYP-6 & 3 & & $6 \phi 8$ & 1.79 & 16 & $\begin{array}{lll}\bullet & 0 & 0 \\
\bullet & \bullet & 0\end{array}$ \\
\hline
\end{tabular}

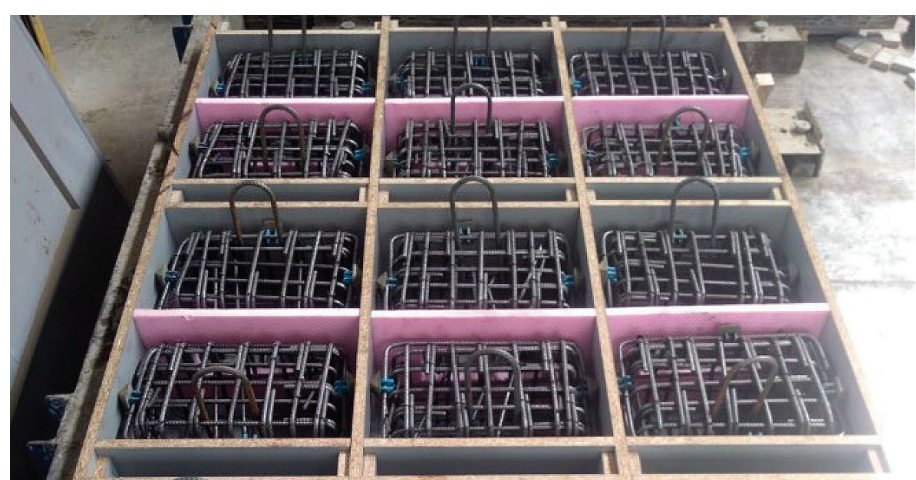

Fig. 1 Test specimen

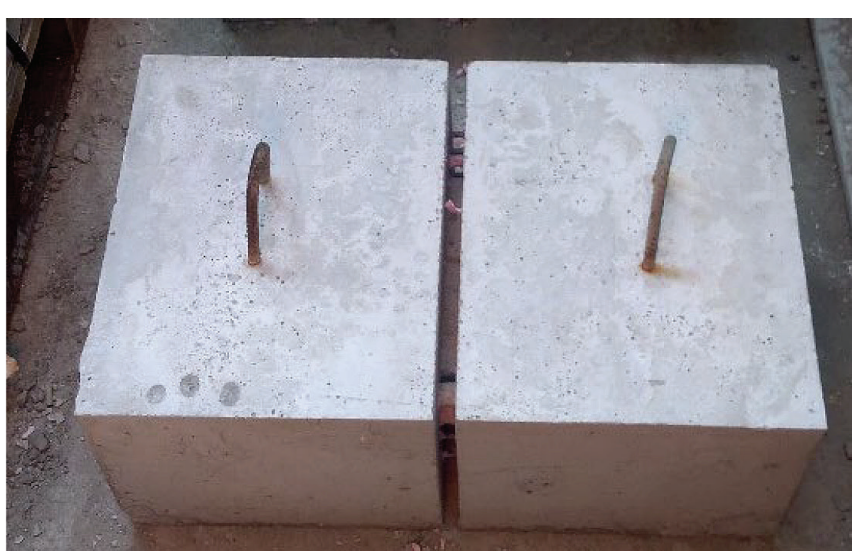




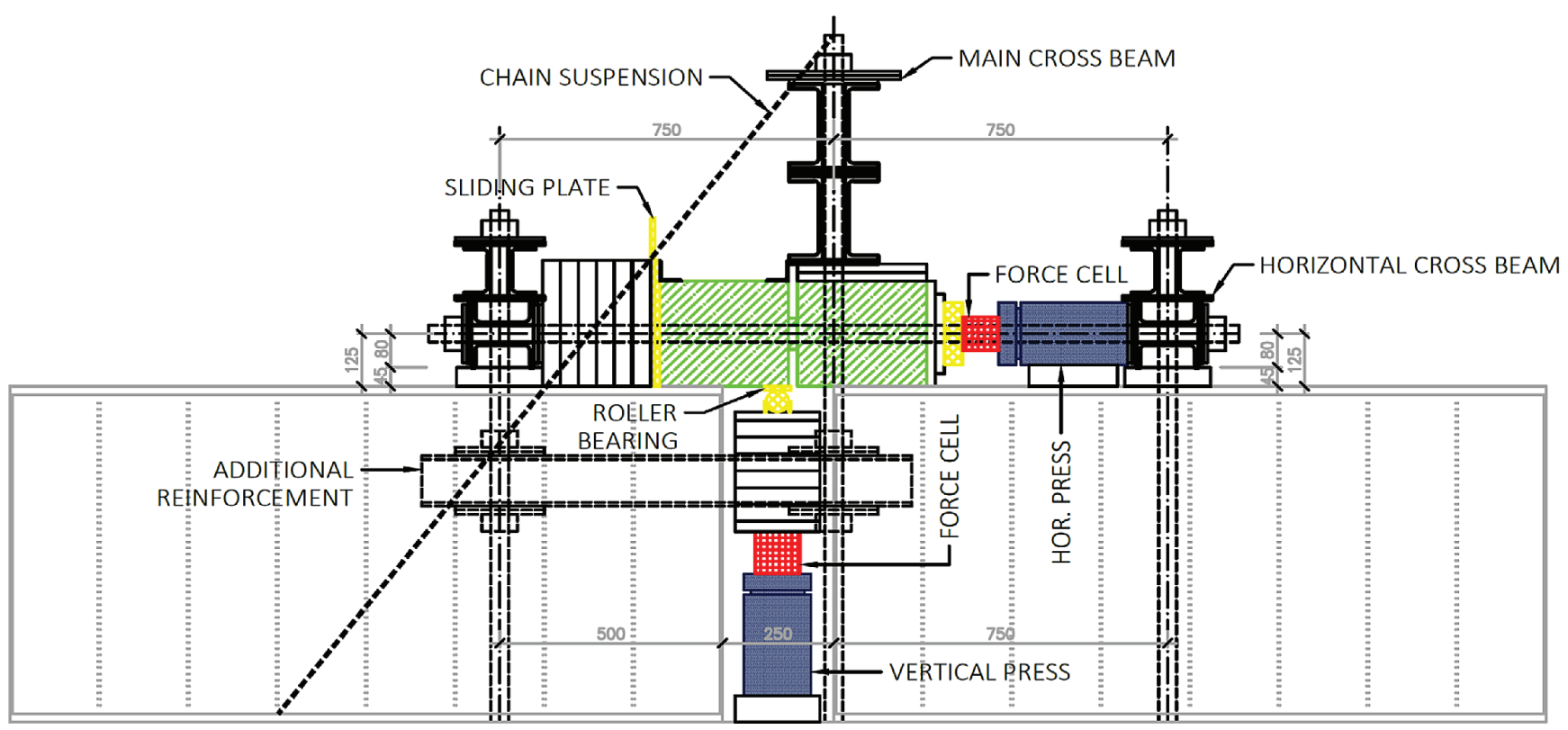

Fig. 1 Test specimen
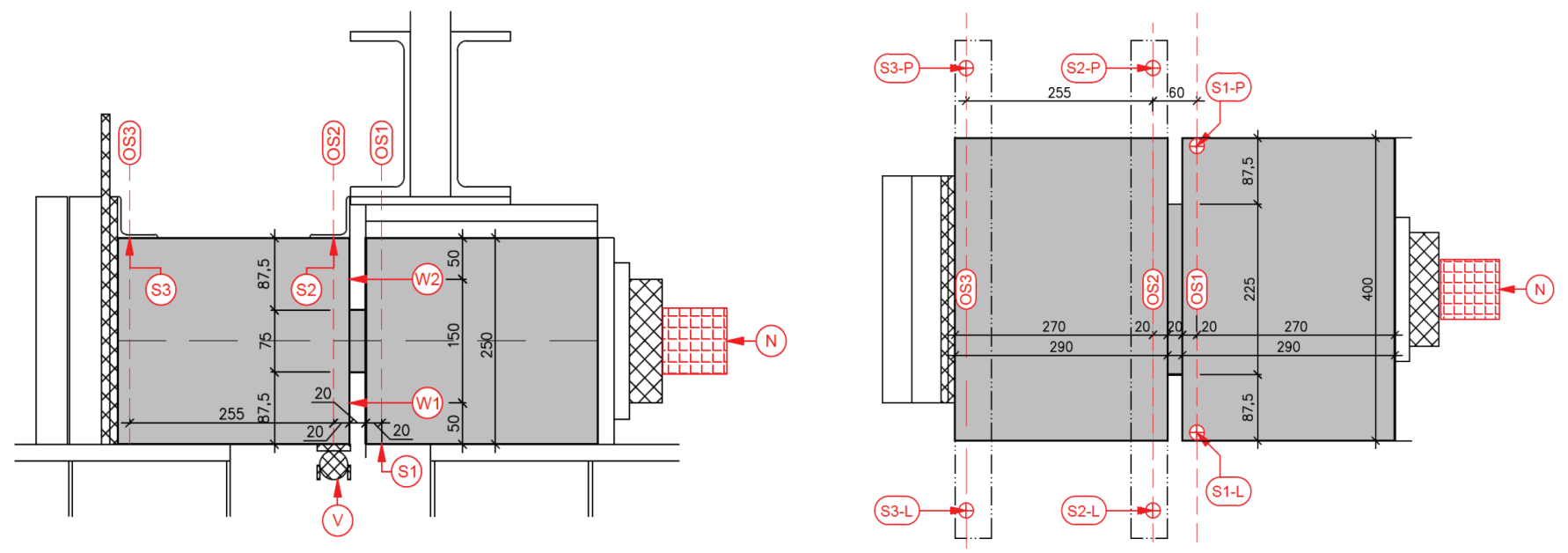

Fig. 3 Setup of the monitoring points

The sample was tested in a horizontal position, so that the vertical deformations would correspond to the deformations that would be caused by the shear force in the joint neck. The deformations were measured with digital displacement gauges (LVDT) in three axes, with two gauges located on each measurement axis, one on the right and one on the left side of the specimen, see Figs. 3a, 3b.

\section{RESULTS}

The test results confirmed the theoretical assumptions according to the shear friction theory, namely:

- Samples with a higher degree of reinforcement achieved higher resistance at the same level of axial force than the specimens where the degree of reinforcement was lower.

- The force-deformation diagram in Fig. 4 shows that at higher levels of axial force, i.e., 300 and $450 \mathrm{kN}$, the increase in strength was more pronounced than at lower values of the axial force. At a normal load of $450 \mathrm{kN}$, it was possible to achieve a ratio of the axial force to the shear force of up to 1: 1 .

- For samples without a reinforced neck (type T0), the failure was not indicated by an increase in deformation, and significant yielding could not be observed due to the insufficient reinforcement of the hinge throat.

Any cracks could not be measured or monitored during the test, so they were only examined after the failure of the specimen. For this reason, it was not possible to determine any changes in their width or to determine their shape and inclination before failure. Based on

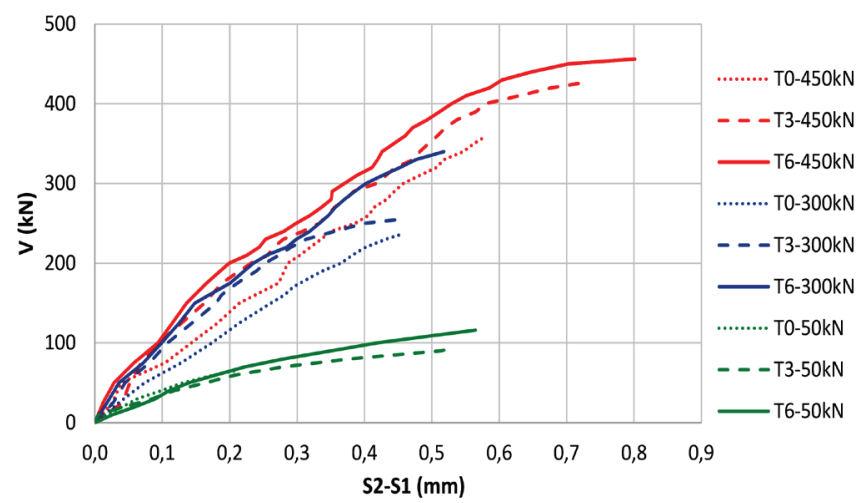

Fig. 4 Test results: force-shear slip diagram 

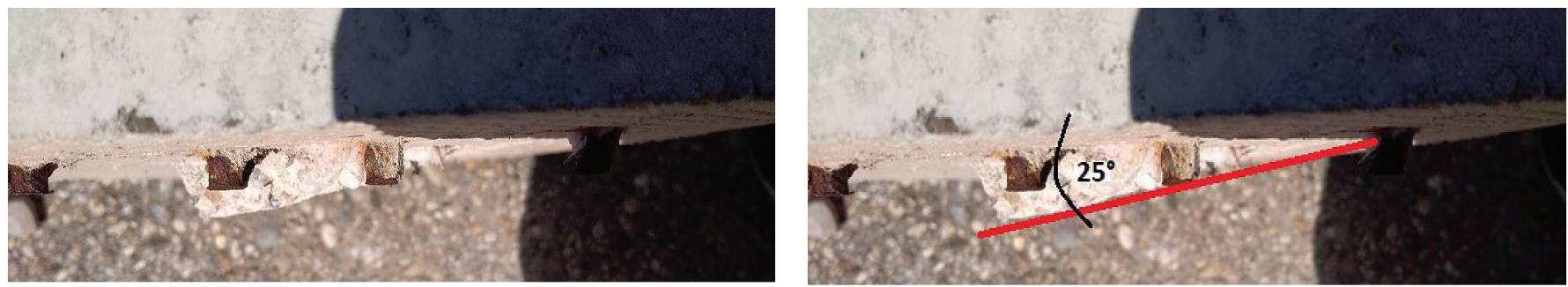

Fig. 5 Shape of the shear crack - unreinforced hinge
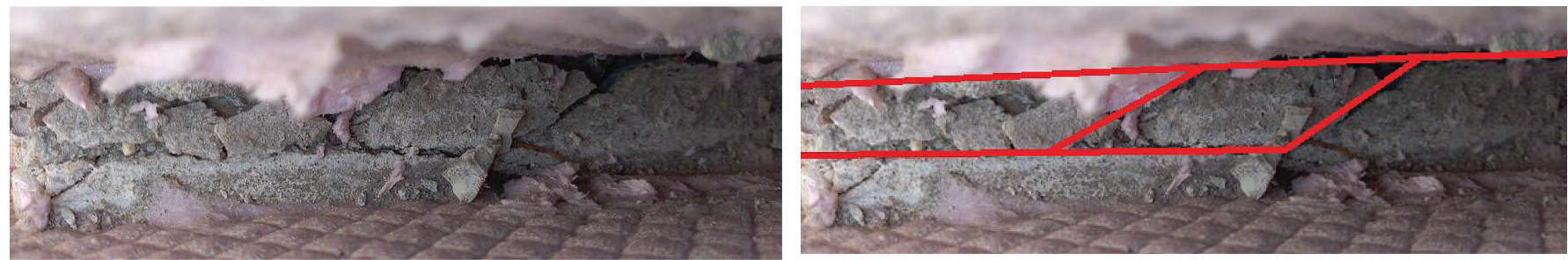

Fig. 6 Shape of the shear crack - reinforced hinge

Tab 3 Comparison of the experimental and design resistance according to the existing models

\begin{tabular}{|c|c|c|c|c|c|}
\hline Type & $V_{R . t e s t}(\mathbf{k N})$ & $V_{R . N}(\mathbf{k N})$ & $V_{R . B}(\mathrm{kN})$ & $V_{R . F}(\mathrm{kN})$ & $V_{R . H}(\mathrm{kN})$ \\
\hline T-0-50 & 65.41 & 13.14 & 17.52 & 13.14 & 35.48 \\
\hline T-3-50 & 91.17 & 13.99 & 18.65 & 13.99 & 81.28 \\
\hline T-6-50 & 116.05 & 13.60 & 18.13 & 13.60 & 123.73 \\
\hline T-0-300 & 237.16 & 77.18 & 102.91 & 77.18 & 208.38 \\
\hline T-3-300 & 254.52 & 73.43 & 97.91 & 73.43 & 241.77 \\
\hline T-6-300 & 339.88 & 76.79 & 102.38 & 76.79 & 294.34 \\
\hline T-0-450 & 358.10 & 112.97 & 150.63 & 112.97 & 305.03 \\
\hline T-3-450 & 426.18 & 115.83 & 154.44 & 115.83 & 356.25 \\
\hline T-6-450 & 456.14 & 113.62 & 151.49 & 113.62 & 393.79 \\
\hline
\end{tabular}

the proposed geometry and method of loading, the formation of a shear crack was assumed only at the hinge throat. The assumptions proved to be correct. This crack passed through the neck of the joint at an angle of $75^{\circ}-90^{\circ}$. Two types of cracks were observed. The first type occurs when a crack is formed at an angle of $75^{\circ}$ and continues crossing diagonally through the hinge throat. This crack occurred in all the specimens without a reinforced hinge, see Fig. 5. The second type of failure occurred in the specimens with a reinforced neck. The cracks evolve at an angle generally greater than $75^{\circ}$. As in the previous case, them start on the active side of the lower edge of the throat, but their progress is parallel to the throat axis. The crack passes to the other side approximately in the middle of the neck at an angle of $40^{\circ}-45^{\circ}$ and then continues along the edge until the end, see Fig. 6. An additional crushing near the hinge area occurred at the shear failure due to a slip of the hydraulic press, which resulted in the formation of additional cracks in the throat. For this reason, it was not possible to accurately identify the crack that occurred at the time of the sample's failure. The magnitude of the normal force did not affect the shape of the crack.

\section{EVALUATION OF THE EXPERIMENTS}

The experimental values of the shear force were compared with the computational resistance according to the existing models for the design of concrete hinges and with the resistance calculated according to ESF. The mean values of the material parameters were used in the calculation.

\subsection{Existing models for the design of notched joints}

In this case, the value of shear resistance mainly depends on the magnitude of the axial force at the hinge area. An overview of design formulas according to the individual models is given in Table 3 . The comparison of the shear force at the time of failure during the experimental measurements and the calculated shear resistance is in the following table:

It may be deduced from the given values that the German, British and French models significantly underestimate actual shear capacity. The accuracy of these models declines with an increasing degree of reinforcement, as they do not take this parameter into account in any way. The same trend can be observed with samples loaded with a low axial force, where the quality of the concrete or the parameters of the shear interface are also not taken into consideration.

The opposite problem can occur if these models are used with cases of high values of the axial force when the calculated shear resistance can exceed the strength parameters of the material and thus overestimate the resistance of the concrete strut. However, it should be noted that these models have been used for bridge designs for 


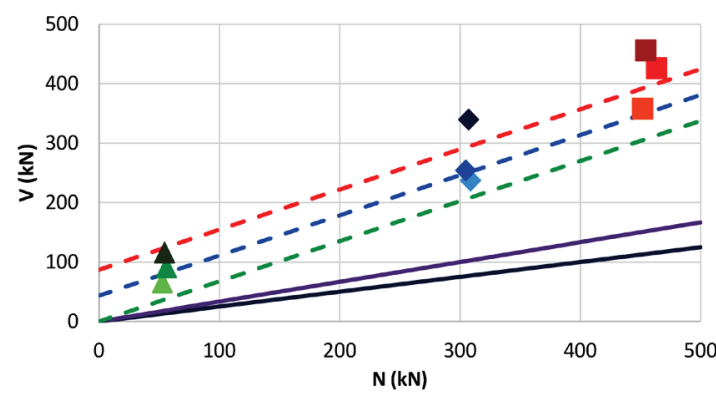

- TO- $50 \mathrm{kN}$

- T0-300kN

- T3-300kN

- T6-300kN

- T0-450kN

- $\mathrm{T} 3-450 \mathrm{kN}$

- T6-450kN

VR-N-F

-VR-B

- VR-H-O $\$ 8$

- VR-H-3ф8

$\mathbf{N}(\mathbf{k N})$

Fig. 7 Comparison of experimental and design resistance according to the existing models

over 60 years and that no hinge failure thus far has been recorded. By following the complete calculation procedure, including the design of the geometry and reinforcement, the principles for the correct conceptual design of bridges and the ranges of loads and deformations common to bridge construction, the use of any of these models is safe in terms of shear resistance. The Herzog model (Herzog, 2005) shows the same trends as the German or French models. However, the values of shear resistance when compared to the results of the experimental measurements are much more accurate than in the previous case. At low levels of the axial force, this model even slightly overestimates the actual shear resistance. This model was developed specifically for the design of the railway bridge in Rupoldingen, Germany; therefore, it gives a very accurate estimate of the shear resistance only for a certain range of the degree of reinforcement and the axial force in the hinge. One of the assumptions of this model is that it considers the full value of the shear resistance of the connectors in the neck. However, according to the shear friction theory, this assumption is incorrect, because the full shear strength of steel is not activated at such levels of low shear deformations.

\subsection{Shear resistance using extended shear friction theory (ESF)}

The scope and field of application of the extended shear friction theory (ESF) corresponds to the nature of the stress to which a concrete hinge is subjected. To verify this assumption, the experimental values of shear force were compared with the resistance according to ESF. The calculation of the shear resistance is different for reinforced and unreinforced elements, respectively, if the failure has a ductile (ESF-D) or brittle character (ESF-B), see Formulas (1) and (2). The interface parameters used in the calculations were taken from (Randl, 2013). A "very rough" sliding interface with a roughness coefficient of $R_{t} \geq 3.0 \mathrm{~mm}$ was used. This type of interface is closest to the monolithic intact interface used in the test specimens. Since these parameters were obtained experimentally and their values have been experimentally verified, the only indefinite parameter remains the compressive strength of the concrete. In contrast to conventional shear interfaces, there is a three-axial stress state at the hinge throat. This fact was not considered; therefore, a comparison of the results was performed using both the mono-axial and triaxial compressive strengths of the concrete. The tri-axial strength was obtained by multiplying the strength $f_{c k}$ with the factor $F$, where $F$ is calculated according to (3):

$$
\begin{gathered}
F=\sqrt{F_{a} F_{b}} \\
F_{a}=\min \left[3 ; \frac{d}{a}\right] \\
F_{b}=\min \left[3 ; \frac{c}{b}\right]
\end{gathered}
$$

Where: $a, b$ are the width and length of the hinge throat $c, d$ are the width and length of the connected prism

It can be observed that at the shear interfaces where there is a high level of normal stress, friction is a crucial component of the overall resistance. The experimental shear force already exceeded the design resistance 2 to 3 times at the level of the normal stress value at $75 \%$ of the compressive strength of the concrete. The resistance according to ESF is limited by the resistance of the concrete. If the value of the mono-axial strength of concrete is used, the design values are significantly underestimated and do not correspond with the experiment. Assuming the unique geometry of a concrete hinge, the fact that the failure of the specimens occurred only in the area of the neck and that a tri-axial state of stress is created in this area, it is reasonable to use the increased strength of the concrete in the calculations. It should be noted that according to previous research on concrete hinges, a normal stress 4-6 times higher than the com-

\begin{tabular}{|c|c|c|c|c|c|c|}
\hline & \multirow{2}{*}{$\mathbf{V}_{\mathrm{R}, \text { test }}(\mathbf{k N})$} & \multicolumn{5}{|c|}{$\mathbf{V}_{\mathrm{R}}(\mathbf{k N})$} \\
\hline & & ESF-B-V1 & ESF-D-V1 & ESF-B-V2 & ESF-D-V2 & EN 1993-1 \\
\hline T0B-50 & 65.41 & 56.37 & 42.23 & 56.37 & 43.98 & 0.0 \\
\hline T3B-50 & 91.17 & - & 70.43 & - & 72.01 & 43.50 \\
\hline T6B-50 & 116.05 & - & 93.17 & - & 94.59 & 87.0 \\
\hline T0A-300 & 237.16 & 144.96 & 144.96 & 235.68 & 223.17 & 0.0 \\
\hline T3A-300 & 254.52 & - & 144.96 & - & 246.03 & 43.50 \\
\hline T6B-300 & 339.88 & - & 152.19 & - & 271.52 & 87.0 \\
\hline T0B-450 & 358.10 & 152.19 & 152.19 & 335.90 & 321.76 & 0.0 \\
\hline T3B-450 & 426.18 & - & 152.19 & - & 351.46 & 43.50 \\
\hline T6B-450 & 456.14 & - & 152.19 & - & 351.46 & 87.0 \\
\hline
\end{tabular}
pressive strength of concrete can be observed. The conservative val-

Tab 4 Shear resistance according to ESF 

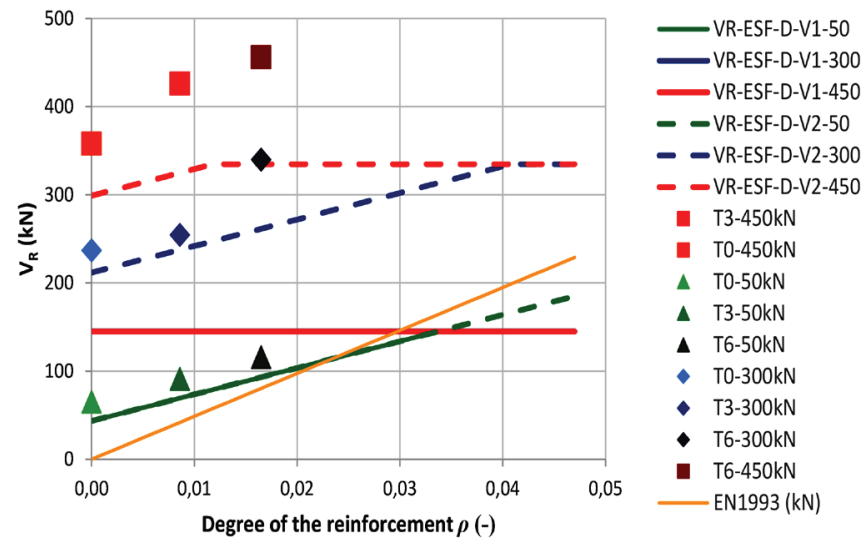

Fig. 8 Comparison of the experimental and design resistance according to ESF

ue of this strength can be calculated, for example, according to STN EN 1992. By using a higher compressive strength in the calculations, a better correlation with the experiment may be observed, see Fig. 8. Due to the limitations of the test setup, it was not possible to achieve a higher level of normal stress than the monoaxial compressive strength of the concrete in the throat.

\section{NUMERICAL VERIFICATION OF RESULTS}

For numerical verification of the results, the Atena 3D v.5.6.1.17830 program was used. A 3D FEM model of the specimen, including the reinforcement and the anchor plates, was created. "Brick" elements were selected for all the concrete parts. Tetrahedral elements were used only for the support steel plates.

The size of the finite elements was appropriately selected and optimized during the analysis. The stiffness of the test assembly was not considered. The steel plates were $40 \mathrm{~mm}$ thick and made of an isotropic, elastic material (CC3DElastIsotropic) with an artificially increased modulus of elasticity of $2100 \mathrm{GPa}$ to evenly redistribute the load applied. Interface elements (GAP) were used to simulate the interaction of the support plates and the concrete surface of the sample so that only the compressive load could be transmitted. The reinforcement was modeled in the form of a 1D element with a bilinear stress-strain working law and with complete cohesion. The load applied and the deformation of the specimen were tracked by monitoring points. The load was applied through steel support plates in the form of a controlled deformation.

Atena uses a cumulative loading method. In the first step, axial force was applied at a rate of $10 \mathrm{kN}$ per step until the desired value

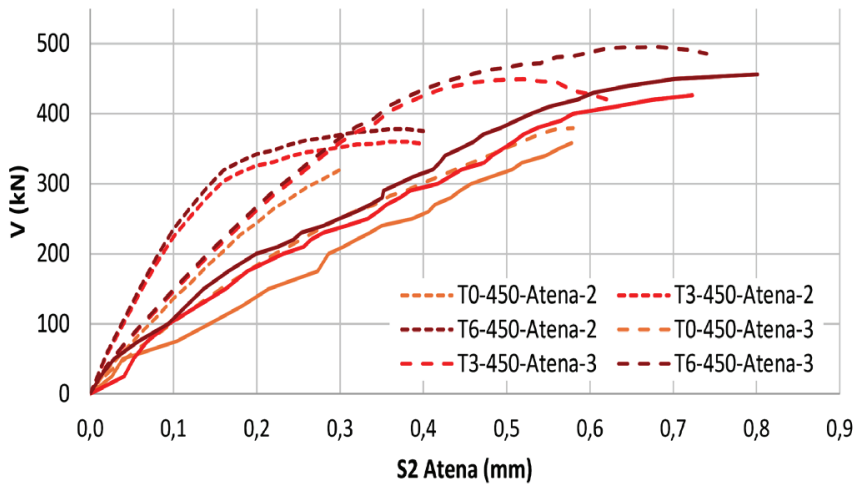

Fig. 10 Comparison of the experimental results with the numerical analysis $-450 \mathrm{kN}$ series
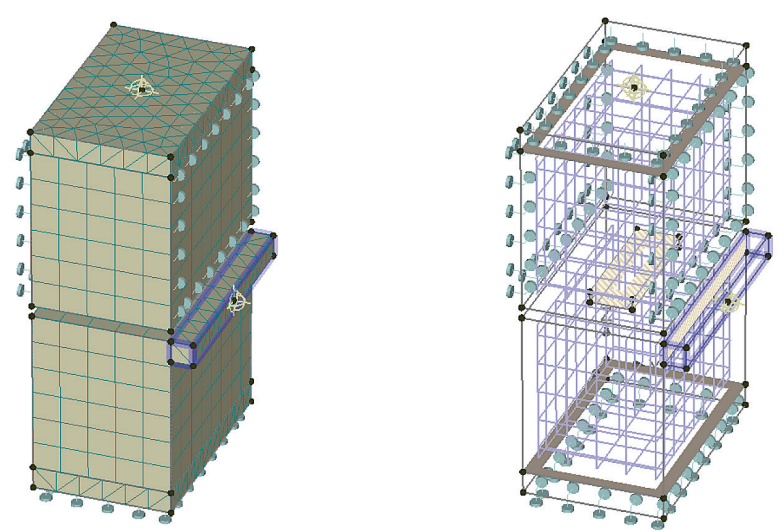

Fig. $93 \mathrm{D}$ model of the concrete hinge in the Athena program

of the axial load was reached. Subsequently, the transverse deformation increments at a speed of $0.01 \mathrm{~mm} / \mathrm{step}$ in the first 20 load steps and then $0.02 \mathrm{~mm} / \mathrm{step}$ to failure. A standard Newton-Raphson method was used for the solution.

The recommended material model for the concrete is the fracture plastic CC3DNonLinCementitious2 model, where the compressed area is defined by plasticity and the tensile failure by fracture mechanics. An alternative to this material is CC3DNonLinCementitious3. This material model is a more advanced version of the previous one and has an increased deformation capacity of concrete at a triaxial stress (Červenka et al., 2018). For each specimen, the calculations were performed for both material models, see Fig. 10. It can be seen there that for the first material model, the failure occurred at deformations of around $0.3 \mathrm{~mm}$, while in the case of the second model, the deformations were significantly greater. The numerical analysis confirmed the theoretical assumptions mentioned above, and a good agreement with the test results was also achieved.

However, significant deviations in the deformations occurred in the case of some of the specimens, for example, in the case of the T3450 and T6-450 samples. These deviations were probably caused due to the faster loading during the test. Also, the course of the deformations using the CC3DNonLinCementitious 3 material model shows a significantly better agreement with the experiment. The Atena program permits displaying the course and orientation of any cracks in the finite elements. A crack fixation factor of 1 was used in the calculations. The following figure shows orientation of the cracks in the FEM model and the attributable test specimen.

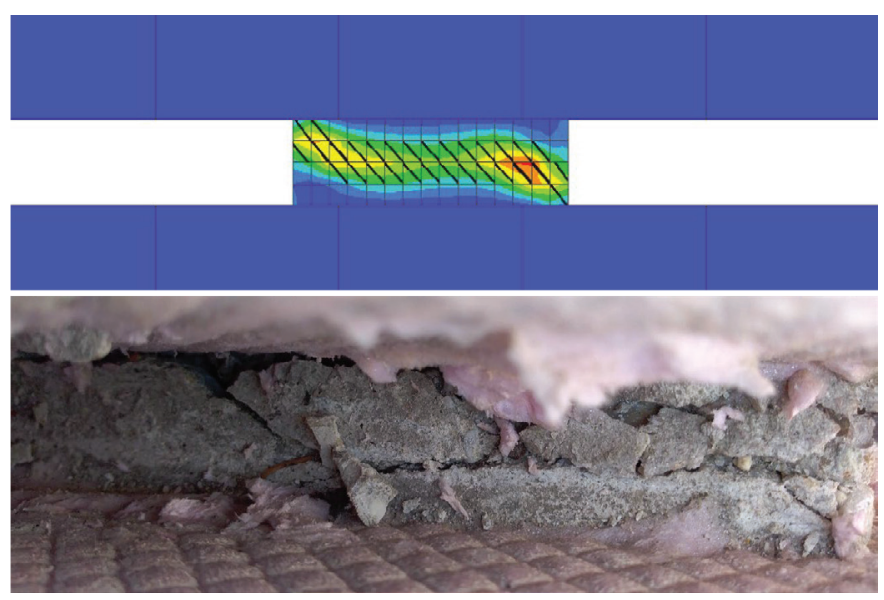

Fig. 11 Comparison of the orientation of the shear crack 


\section{CONCLUSION}

The experimental program consisted of tests of the shear resistance of concrete hinges loaded with a centric axial and shear force. The aim of the experimental program was to verify the validity of existing models for the design and assessment of the shear resistance of concrete hinges. At the same time, the applicability of the extended shear friction theory was reviewed. Test results from similar experiments applicable to this type of construction could not be found, so that the scope of the data acquired is partly limited by the low value of the axial load. Therefore, the conclusions are drawn only on the basis of the data obtained from the experimental program performed.

1. A comparison of the experimental and theoretical resistance according to the existing models showed that the resistance calculated according to these models significantly underestimates the actual resistance of the samples tested by approximately 3-4 times. Likewise, these models do not in any way take into account the interface parameters, where the M. Herzog model is the only exception.

2. The comparisons of the test results with calculation according to the design model based on the extended shear friction theory showed a better level of agreement with the experiment, while underestimating this resistance by approximately two- fold, but only. A design based on this theory enables considering the nature of the concrete failure and the method of loading, as well as some material and geometric parameters of the sliding interface.

3. It was proposed to modify the input parameters, namely, the compressive strength of the concrete with respect to the tri-axial stress in the hinge throat. The effect of this modification was that the difference between the theoretical and experimental resistance decreased by $10-30 \%$.

4. The experiment shows that a three-axial stress state has an effect on the shear resistance of concrete hinges. However, the experimental setup did not allow reaching a higher normal stress at the hinge throat. It is thus not yet possible to draw definitive conclusions.

\section{Acknowledgments}

This work was supported by the Agency for the Support of Research and Development on the basis of Contract No. APVV-15-0658. The project was implemented with the financial support of the Scientific Grant Agency of the Ministry of Education and Science of the Slovak Republic. The registration number of the project is VEGA No. 1/0522/20 and VEGA No. 1/0645/20

\section{REFERENCES}

BVVVTK Bro 08, VV (2008) http://documents.vsect.chalmers.se/ structuralengineering/SorenLindgren/bro/Bro08.pdf.

CS 468. (2020) Assessment of Freyssinet concrete hinges in highway structures. Design Manual for Roads and Bridges: Highway Structures \& Bridges. Highways England.

Červenka V. - Jendele L. - Červenka J. (2018) ATENA Program Documentation, Part 1, Theory, Prague.

Fib. Special Activity Group 5 (2011) Fib Model Code 2010, Fib Special Activity Group 5, pp. 287-296.

Halvoník J. - Majtanová L. (2018) Experimental Investigation of the Maximum Punching Resistance of Slab-Column Connections, Slovak Journal of Civil Engineering, pp 22-28. doi:10.2478/sjce2018-0017.
Herzog M. (2005) Wirtschaftliche Stahlbeton- und Spannbetonbemessung, Band 5 Spezialprobleme, Bauwerk-Verlag, Berlin, 2005, No. 31, pp. 1-25

Marx, S. - Schacht, G. (2010) Betongelenke im Brückenbau: Bericht zum DBV Forschungsvorhaben 279). Deutscher Beton- und Bautechnik - Verein E.V., Berlin, Slovakia

NEN: NEN 6723 (1995) Regulation for concrete - (VBB 1995) Bridges - Structural requirements and calculation methods. NEN.

Règles BAEL 91 modifiées 99 (1999) Règles techniques de conception et de calcul des ouvrages et constructions en béton armé suivant la méthode des états-limites, Editions Eyrolles.

Randl, N. (2013) Design recommendations for interface shear transfer in fib Model Code 2010, Structural Concrete, pp. 230-241. doi:10.1002/suco.201300003. 